\title{
Nano-SIMS Research at the Environmental Molecular Sciences Laboratory
}

\author{
Z. Zhu and C.M. Mahoney
}

Environmental Molecular Sciences Laboratory, Pacific Northwest National Laboratory, 902 Battelle Blvd, Richland, WA 99352 USA

We present early results from a newly acquired NanoSIMS 50L instrument at the Environmental Molecular Sciences Laboratory (EMSL), a state-of-the-art user facility located at Pacific Northwest National Laboratory (PNNL). NanoSIMS has been proven to be a useful tool for environmental research where it has been used quite regularly now for analysis and imaging of isotopically labelled materials metabolized by living organisms [1,2], as well as several geochemical $[3,4]$, environmental $[5,6]$ and cosmochemical [7-9] applications. Here we describe our recent efforts to develop NanoSIMS for analysis and characterization of various environmental samples, ranging from microbial samples to actinides.

The NanoSIMS is a high spatial resolution imaging mass spectrometer that can be used to obtain elemental and/or isotopic information from samples with excellent sensitivity (ppm, ppb) and precision. A primary ion beam $\left(\mathrm{Cs}^{+}\right.$or $\left.\mathrm{O}_{2}^{-}\right)$is focused onto the sample surface, where the extraction assembly and primary focusing optics are placed extremely close to and normal to the surface, thus allowing for a significant reduction in spot size (as low as $25 \mathrm{~nm}$ ) as compared to other SIMS designs. The primary ions generate secondary ions which are extracted into a magnetic sector with a multi-collector detection chamber; allowing for precise analysis of elemental and isotopic compositions.

Elemental and isotopic imaging in microbial samples is often required in order to better understand complex mechanisms including photosynthetic processes, as well as carbon and nitrogen cycling in soils. This is an active area of research at EMSL. Figure 2 shows preliminary data acquired with the nanoSIMS $50 \mathrm{~L}$ of a single prokaryotic cell. This method will be used for analysis of nitrogen uptake from cyanobacteria communities during light/dark cycles.

An example is displayed in Figure 1, which shows the diffusion of isotopic species in glass. The image shows the diffusion of ${ }^{29} \mathrm{Si}$ to the interface in ${ }^{29} \mathrm{Si}$ enriched glass after being stored in natural abundance ${ }^{28} \mathrm{Si}$ saturated water. As can be seen, both ${ }^{29} \mathrm{Si}$ and Boron are depleted at the interface. The diffusion layer is $\sim 500 \mathrm{~nm}$ thick and is easily observed as well as smaller porous domains (bright regions in top images). As can be seen the NanoSIMS is an ideal tool for understanding complex diffusion processes.

\section{References:}

[1] Lechene, C.; Hillion, F.; McMahon, G.; Benson, D.; Kleinfeld, A. M.; Kampf, J. P.; Distel, D.; Luyten, Y.;

Bonventre, J.; Hentschel, J. Biol. 2006, 5(6), 20.

[2] Lechene, C. P.; Luyten, Y.; McMahon, G.; Distel, D. L. Science. 2007, 317 (5844), 1563.

[3] Herrmann, A. M.; Ritz, K.; Nunan, N.; Clode, P. L.; Pett-Ridge, J.; Kilburn, M. R.; Murphy, D. V.; O'Donnell, A. G.; Stockdale, E. A Soil Biology and Biochemistry. 2007, 39 (8), 1835-1850.

[4] Orphan, V. J.; House, C. H. 2009, Geobiology 7 (3), 360-372.

[5] Finzi-Hart, J. A.; Pett-Ridge, J.; Weber, P. K.; Popa, R.; Fallon, S. J.; Gunderson, T.; Hutcheon, I. D.; Nealson, K. H.; Capone, D. G. PNAS 2009, 106 (15), 6345.

[6] Clode, P. L.; Kilburn, M. R.; Jones, D. L.; Stockdale, E. A.; Cliff III, J. B.; Herrmann, A. M.; Murphy, D. V. Plant Physiology 2009, 151 (4), 1751-1757.

[7] Briani, G.; Gounelle, M.; Marrocchi, Y.; Mostefaoui, S.; Leroux, H.; Quirico, E.; Meibom, A. PNAS 2009, 106 (26), 10522-10527.

[8] Matzel, J. E. P.; Ishii, H. A.; Joswiak, D.; Hutcheon, I. D.; Bradley, J. P.; Brownlee, D.; Weber, P. K.; Teslich, N.; Matrajt, G.; McKeegan, K. D. Science 2010, 328 (5977), 483.

[9] Boxer, S. G.; Kraft, M. L.; Weber, P. K. Ann. Rev. Biophys. 2009, 38, 53-74. 
Figure 1. ${ }^{29} \mathrm{Si}$ enriched SON68 glass sample, leaching in natural abundance Si saturated water for 1 year. Imaging of ${ }^{28} \mathrm{Si},{ }^{29} \mathrm{Si}$ and ${ }^{10} \mathrm{~B}^{16} \mathrm{O}_{2}$ are shown in the top images. The ratio of ${ }^{29} \mathrm{Si} /{ }^{28} \mathrm{Si}$ is shown in the bottom left.

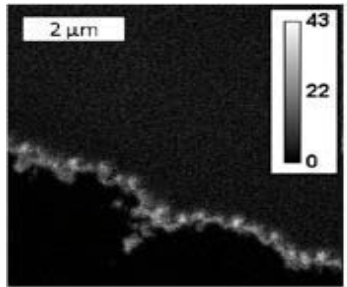

${ }^{28} \mathrm{Si}$

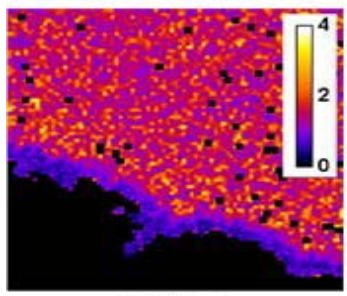

${ }^{29} \mathrm{Si} /{ }^{28} \mathrm{Si}$

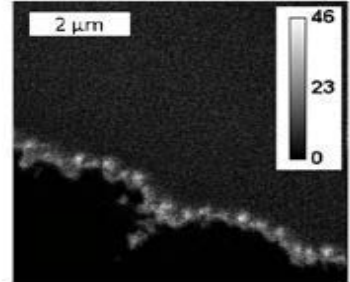

${ }^{29} \mathrm{Si}$

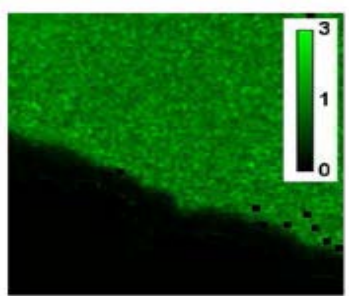

Normalized ${ }^{10} \mathrm{~B}^{16} \mathrm{O}_{2}$

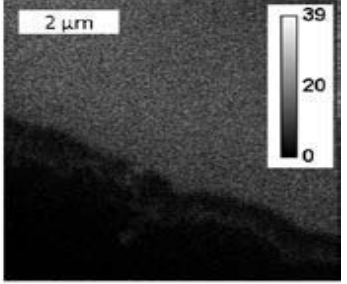

${ }^{10} \mathrm{~B}^{16} \mathrm{O}_{2}$

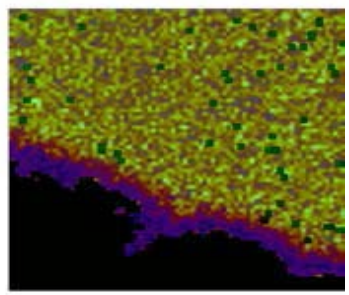

Overlay

Figure 2. Left Panel: Optical image of cyanobacteria dried on a Si wafer prior to analysis with NanoSIMS. Right Panel: NanoSIMS high spatial resolution imaging of single cyanobacterium where red $=\mathrm{Si}$-, green $=\mathrm{CN}$ - from protein signals, and blue are $\mathrm{PO}_{2}{ }^{-}$signals characteristic of cell/organelle membrane species contained inside the cell.
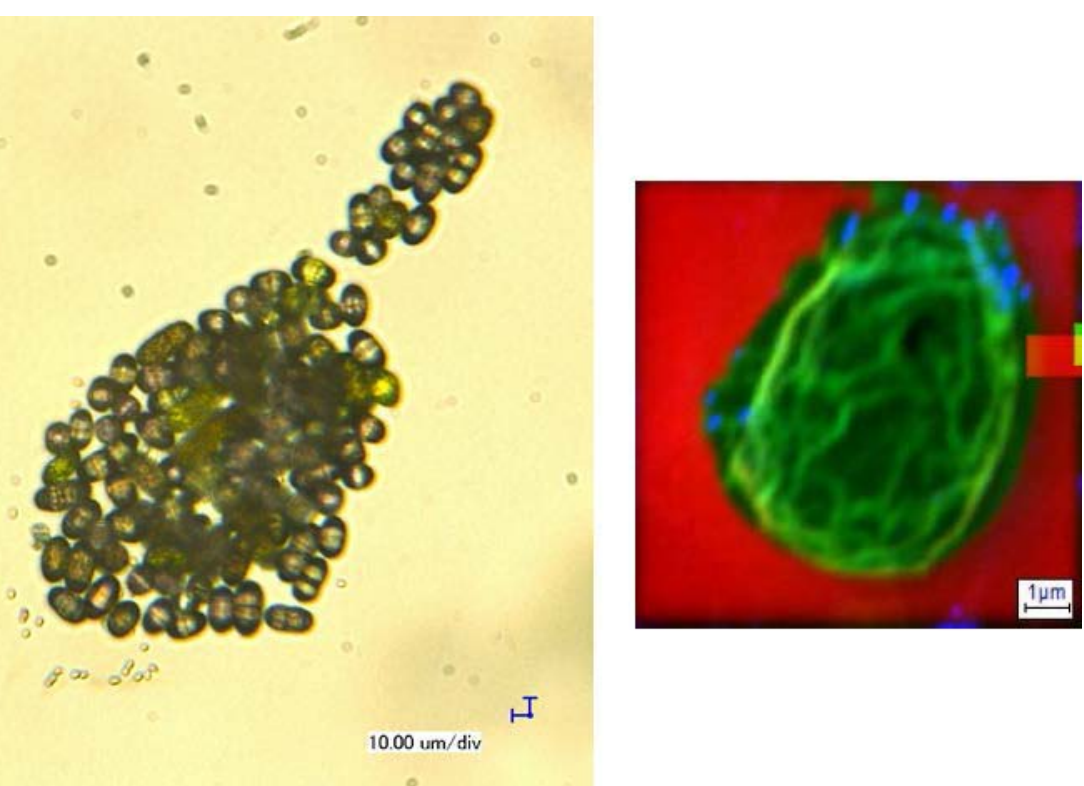